\title{
ANÁLISE DE DUAS PROPOSTAS DE ATIVIDADE EXPERIMENTAL SOBRE MOMENTO DE UMA FORÇA NAS AULAS DE CIÊNCIAS PARA O ENSINO FUNDAMENTAL
}

\author{
EMERSON AVELINO MEDEIROS* FABIO RAFAEL SEgundo ${ }^{\dagger}$ \\ MARCIO RODRIGO LOOS \\ Universidade Federal de Santa Catarina, Blumenau, Brasil \\ Universidade Federal de Santa Catarina, CEP 89036-256, Blumenau / SC, Brasil
}

\begin{abstract}
Resumo
O presente trabalho tem por objetivo comparar duas atividades, uma elaborada na forma de experimentação convencional e outra na forma de experimentação em laboratório virtual, para o ensino de Momento de uma Força nas aulas de Física dos estudantes do $9^{\circ}$ ano do Ensino Fundamental II. Para tanto, foi confeccionado um roteiro experimental para cada uma das atividades e discutidas vantagens e desvantagens na preparação das mesmas, na execução pelo professor e pelo aluno. Os resultados das comparações foram significativos e demonstraram as particularidades que cada atividade possui, além de evidenciarem a igual importância de ambas, uma vez que a aprendizagem pode ocorrer nas duas formas de experimentação.
\end{abstract}

Palavras-chave: Experimentação, Ensino de Física, Ensino Fundamental.

\footnotetext{
*E-mail: emer.medeiros@gmail.com.

${ }^{\dagger}$ E-mail: fabio.segundo@ufsc.br.

‡E-mail:marcio.loos@ufsc.br.
} 


\begin{abstract}
The present study aims to compare two activities, conventional experimentation and experimentation in a virtual laboratory, for the teaching of Moment in the Physics classes of students belonged to 9th year of Middle School. In order to do this, an experimental script was prepared for each one of the both experimentation activities and discussed among them advantages and disadvantages in the preparation of the activity, in the execution by the teacher and in the execution by the student. The results of the comparisons demonstrated the particularities that each activity has; in addition, they have shown the importance of both, since the learning can occur in both types of experimentation.
\end{abstract}

Keywords: Experimentation, Physics Teaching, Middle School.

\title{
1 Introdução
}

É evidente a necessidade de uma reformulação dos processos de ensino utilizados por uma grande parcela de professores de Física de nosso país. Segundo Santos [1], o ensino de Ciências continua sendo uma caricatura muito pobre daquilo que o conhecimento científico requer na formação dos estudantes. E o currículo da disciplina de Física é baseado em fórmulas e definições desvinculadas das necessidades da formação dos estudantes e de conhecimentos científicos relevantes.

Libânio [2] diz que a atividade de ensinar, na educação brasileira, é vista comumente, como transmissão da matéria aos alunos, realização de exercícios repetitivos, memorização e definições de fórmulas e conceitos.

A utilização de atividades experimentais está presente na maioria das sequências de ensino e aprendizagem e é uma das formas mais populares e reconhecidamente eficientes para o ensino de Física. Segundo Rosito [3], a utilização da experimentação é considerada para o ensino de Ciências, como essencial para a aprendizagem científica. No entanto, devido à falta de laboratório, de tempo ou de conhecimento específico, muitos professores optam pelo método que dá menos trabalho, ou seja, exposição de conteúdo, memorização, etc.

Neste trabalho é realizada a comparação de dois tipos de experimentação: a atividade experimental convencional e a realizada em ambiente virtual. O objetivo desse artigo é avaliar as vantagens e desvantagens de ambos e motivar os professores para a utilização das atividades em suas aulas. Para isso, foram criados dois roteiros de experimentação sobre o mesmo tema: Momento de uma Força, destinados ao $9^{\circ}$ ano do Ensino Fundamental II. Decidiu-se trabalhar com esse tema pois é de fácil compreensão, facilmente se faz relação com o cotidiano dos alunos e o ambiente virtual é bastante atrativo para estudantes. 


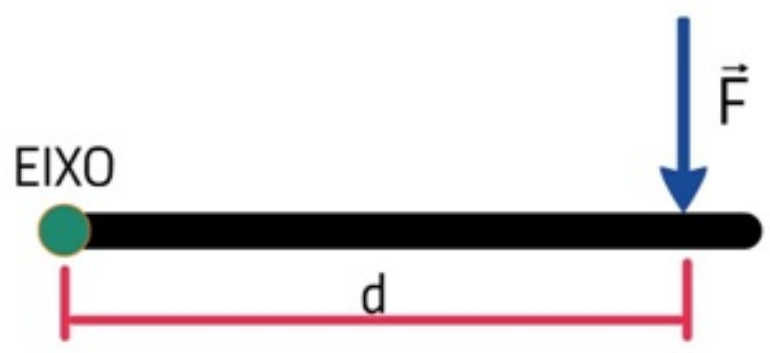

Figura 1: Força aplicada em um corpo a uma distância d.

\section{O experimento}

Para afirmar que um corpo extenso - e.g. uma balança de equilíbrio - esteja em equilíbrio estático é necessário que ele não esteja em movimento de translação e que também não rotacione.

Segundo Ramalho Junior, F. et al. [4], a grandeza física que relaciona força e rotação em um ponto é chamada de Momento de uma Força.

O momento (M) de uma força é a capacidade dessa força girar (rotacionar) um objeto. Para calcular a intensidade dessa grandeza em relação a um ponto de referência (o pólo em torno do qual o corpo irá girar), deve-se obter o produto (multiplicação) da componente da força aplicada perpendicularmente ao corpo pela distância dela até o ponto de giro, isto é:

$$
M=F . d,
$$

onde F é a intensidade da força aplicada perpendicularmente ao corpo, em N (newton) e, d é a distância em m (metros) da força $\vec{F}$ até o referencial de apoio (eixo), conforme Figura 1. A unidade do Momento é N.m.

Momento é uma grandeza escalar, por isso, pode ser positiva ou negativa. O sinal segue a seguinte convenção:

- Quando a Força aplicada fornece uma rotação no sentido anti-horário, em relação ao eixo, o momento é positivo (veja $F_{1}$ na Figura 2);

- Caso a Força aplicada forneça uma rotação no sentido horário, em relação ao eixo, o momento é negativo (veja $F_{2}$ na Figura 2).

Quando a Força é aplicada em uma direção que não forneça rotação, o momento é nulo (veja $F_{3}$ na Figura 2).

No caso da balança de equilíbrio, verifica-se que cada massa colocada exerce uma força peso dado por

$$
P=m g
$$

onde m é a massa que deve ser expressa em $\mathrm{kg}$ e, g é a gravidade local (Na Terra consideraremos igual a $10 \mathrm{~m} / \mathrm{s}^{2}$ ). Nesse caso o momento da força fica

$$
M=m g d .
$$




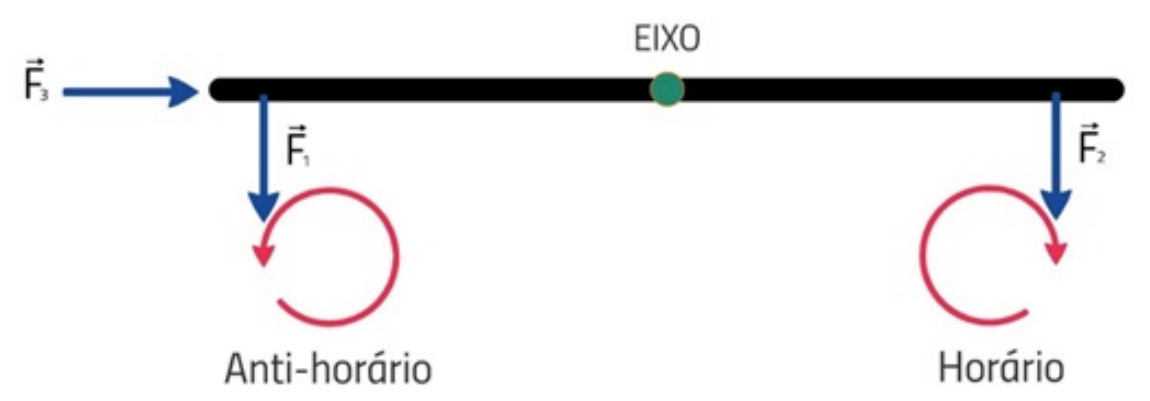

Figura 2: Força aplicada em um corpo a uma distância d.

Sendo assim, se a força peso faz girar a haste no sentido anti-horário, o momento é positivo, caso contrário, negativo. Para que a haste fique em equilíbrio a soma de todos os momentos envolvidos deve ser igual a zero. Para uma situação de $n$ momentos, podemos escrever

$$
M_{1}+M_{2}+\ldots+M_{n}=0 .
$$

\section{Objetivos dos experimentos}

Ao final das atividades de experimentação, espera-se que o aluno identifique como até mesmo massas diferentes podem equilibrar uma balança e possa predizer, ao mudar as posições das massas sobre ela, como afetará seu equilíbrio. Além disso, espera-se que o estudante possa transferir o conhecimento para as situações cotidianas em que envolvem o conceito de momento de uma força e, a partir daí, possam usar esse conhecimento a seu favor.

\section{Experimentação Convencional}

O roteiro de experimentação convencional foi elaborado de forma que o experimento pudesse ser semelhante e comparável ao experimento em laboratório virtual (o qual veremos mais adiante). Além disso, ele deveria permitir que o aparato experimental fosse confeccionado com materiais de fácil acesso para professores ou alunos -, que funcionasse com considerável precisão na medição das grandezas físicas e que pudesse envolver os alunos na resolução dos problemas.

Para a realização da experimentação convencional ${ }^{1}$ são utilizados os materiais listados na Tabela 1.

Na sequência, são apresentados os passos experimentais para a execução da atividade.

Passo 1 - Calibração da balança. Coloque a balança de equilíbrio em uma superfície plana e deixe a haste roscada na posição horizontal para que ela fique estável, ou seja, imóvel, conforme a Figura 3. Caso

\footnotetext{
${ }^{1}$ A execução desta atividade experimental, os roteiros para fabricação das massas e da balança utilizados, bem como o vídeo demonstrando todo o processo de construção, além de estarem no anexo deste trabalho, encontram-se disponíveis no website http://labcti.paginas.ufsc.br/momento/
} 


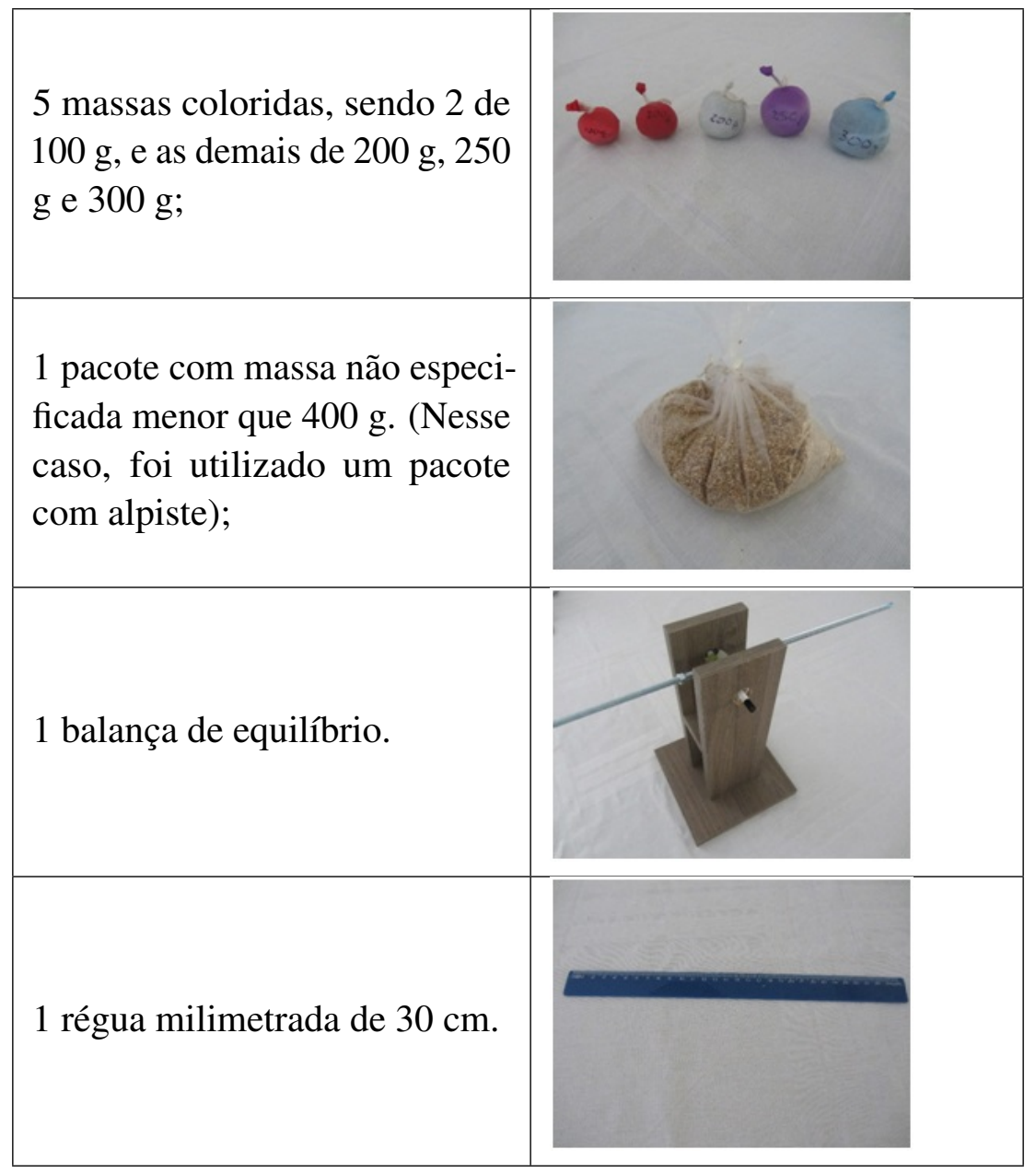

Tabela 1: Materiais usados no experimento.

ela ainda não esteja em equilíbrio, aperte ou afrouxe sensivelmente as porcas 1 e/ou 2 (Figura 4) de forma que seja encontrado o ponto correto em que a haste estabiliza.

Passo 2 - Equilíbrio de massas. Pendure uma massa de $100 \mathrm{~g}$ (vermelha) de um lado da haste da balança e a outra massa de $100 \mathrm{~g}$ (vermelha) do outro lado, de forma que a balança fique em equilíbrio (Não utilizar as porcas de calibração). É importante observar que ao passar a argola da massa pela haste se tome cuidado para não raspar o barbante ou a massa na rosca da haste para não danificar a peça. Também não deixe nenhuma massa em contato com a parte de madeira da balança.

Feito isto, o aluno deve verificar se foi obtido o equilíbrio e deve escrever no relatório o que foi realizado para consegui-lo.

Passo 3 - Neste passo é influído o desafio de número 1 para ser resolvido pelo aluno. Consiste em pendurar de um lado da haste da balança uma massa de $100 \mathrm{~g}$ (vermelha) e do outro lado pendure uma massa de $300 \mathrm{~g}$ (azul) de forma que a haste fique em equilíbrio e obter se foi alcançado o equilíbrio.

Então, o aluno deve escrever novamente no relatório o que fez para conseguir o equilíbrio e a conclusão para que isso tenha acontecido. 


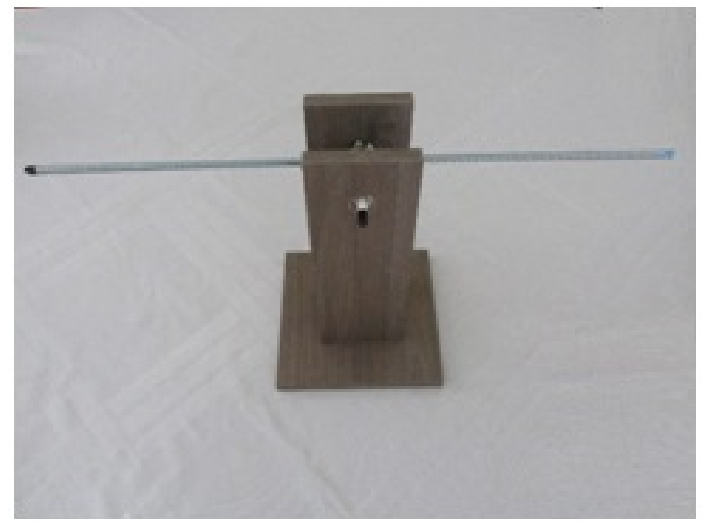

Figura 3: Haste da balança em equilíbrio.

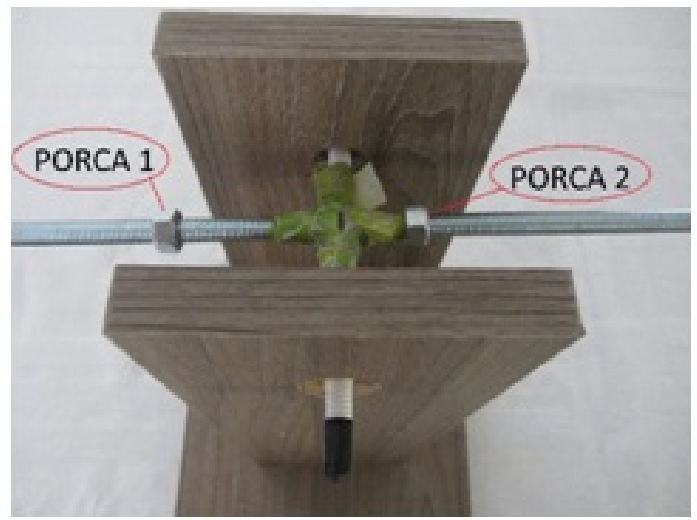

Figura 4: Porcas 1 e 2 para calibração.

Passo 4 - Um segundo desafio ao aluno é proposto neste passo. Neste desafio o aluno deve pendurar na haste da balança todas as 5 massas conhecidas (100 g, 100 g, 200 g, 250 g e 300 g), distribuindo dos dois lados da haste, a fim de encontrar o ponto de equilíbrio, colocando apenas uma massa por posição. Então observa-se novamente se foi encontrado o equilíbrio.

Conforme a Figura 5, deve-se segurar a haste com uma mão para que ela não se mova e utilizando uma régua milimetrada, deve-se medir a distância da marca no eixo até o barbante de cada massa. Com os valores obtidos, deve-se preencher a Tabela 2. Observa-se na Figura 5 que as posições das massas na figura são meramente ilustrativas, pois não mostram as posições das massas na condição de equilíbrio. Nessa figura está sendo medida a distância da massa de 200 g até o eixo, 190 mm.

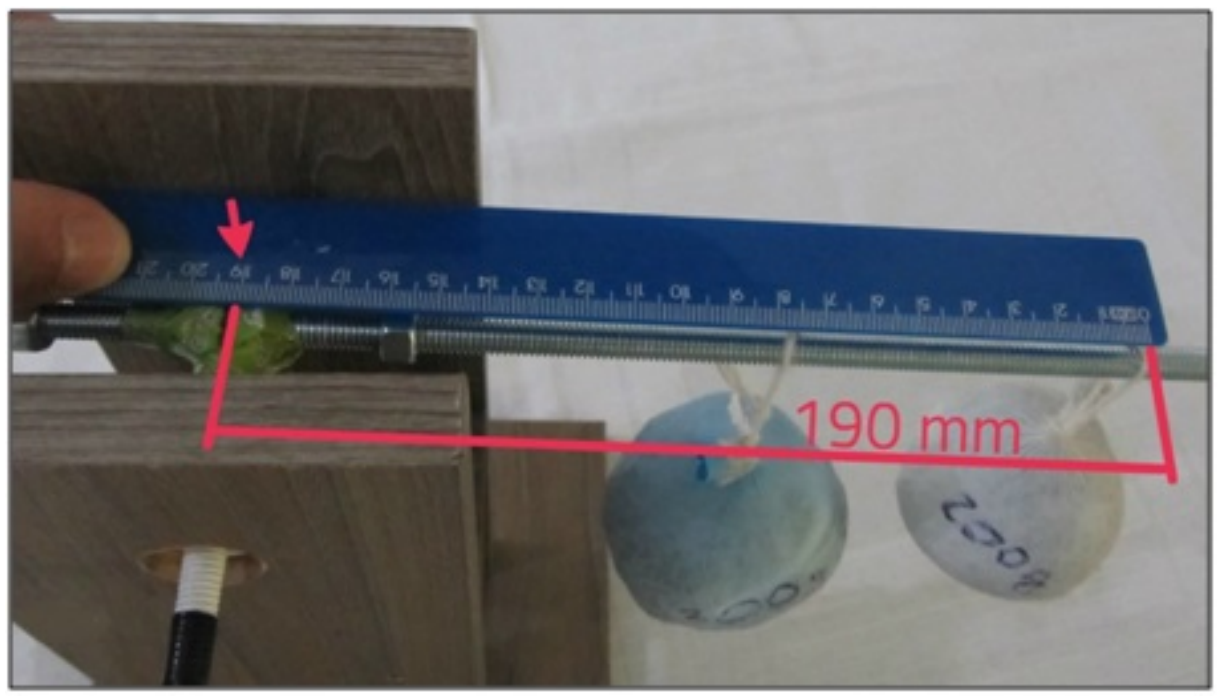

Figura 5: Medições das distâncias das massas em relação ao eixo.

A partir de então, deve-se converter as distâncias para metro e as massas para quilograma dividindo as distâncias medidas em mm e as massas em grama por 1000 e calcular o momento da força. Por exemplo, uma distância de $200 \mathrm{~mm}$ equivale a $0,200 \mathrm{~m}$ e uma massa de $250 \mathrm{~g}$ equivale a $0,250 \mathrm{~kg}$. Utilize a Tabela 
Revista do Professor de Física • Brasília, vol. 2, n. 1 • 2018

Tabela 2: Medições realizadas no Passo 4 - Desafio 2.

\begin{tabular}{|l|c|l|l|}
\hline \multicolumn{2}{|c|}{ Lado Esquerdo } & \multicolumn{2}{c|}{ Lado Direito } \\
\hline Massa (g) & $\begin{array}{c}\text { Distância do barbante } \\
\text { até o eixo (mm) }\end{array}$ & Massa (g) & $\begin{array}{c}\text { Distância do barbante } \\
\text { até o eixo (mm) }\end{array}$ \\
\hline & & & \\
\hline & & & \\
\hline & & & \\
\hline
\end{tabular}

2 na sequência. Considere $g=10 \mathrm{~m} / \mathrm{s}^{2}$ e lembre-se de colocar o sinal negativo para Momentos em que a força peso giraria a haste no sentido horário (conforme Figura 2).

Tabela 3: Cálculos do Passo 4-Desafio 2.

\begin{tabular}{|c|c|c|c|c|c|c|c|}
\hline \multicolumn{3}{|c|}{ Lado Esquerdo } & \multicolumn{4}{c|}{ Lado Direito } \\
\hline $\begin{array}{c}\text { Massa } \\
(\mathrm{kg})\end{array}$ & $\begin{array}{c}\text { Peso } \\
(\mathrm{N})\end{array}$ & $\begin{array}{c}\text { Distância } \\
(\mathrm{m})\end{array}$ & $\begin{array}{c}\text { Momento } \\
(\mathrm{N} . \mathrm{m})\end{array}$ & $\begin{array}{c}\text { Massa } \\
(\mathrm{kg})\end{array}$ & $\begin{array}{c}\text { Peso } \\
(\mathrm{N})\end{array}$ & $\begin{array}{c}\text { Distância } \\
(\mathrm{m})\end{array}$ & $\begin{array}{c}\text { Momento } \\
(\mathrm{N} . \mathrm{M})\end{array}$ \\
\hline & & & & & & & \\
\hline & & & & & & & \\
\hline
\end{tabular}

Passo 5 - Desafio 3: Pendure de um lado da haste da balança uma massa de $100 \mathrm{~g}$ (vermelha) e do outro lado pendure a massa que não sabemos o valor (pacote de alpiste) de forma que a haste fique em equilíbrio.

Conseguiu o equilíbrio? Então, utilizando o cálculo do Momento, identifique o valor da massa de valor desconhecido. Depois disso, repita o procedimento utilizando a massa de $300 \mathrm{~g}$ (azul) ao invés da vermelha de $100 \mathrm{~g}$. Anote os resultados obtidos e, em seguida, responda às cinco questões abaixo:

a. Na Tabela 3, a soma do momento total do lado esquerdo com o momento total do lado direito foi igual a zero? Por quê?

b. Em um parque infantil, Joãozinho, que tem $40 \mathrm{~kg}$ de massa, brinca com seu pai que tem $80 \mathrm{~kg}$. É possível o Joãozinho erguer seu pai na gangorra utilizando apenas seu peso? Por que?

c. Em quais situações no seu dia a dia você gira alguma coisa em torno de um eixo? Em todas elas você pode aplicar o conceito de Momento?

d. Vá até uma porta aberta. Tente empurrar a porta somente com a ponta de um dos dedos de sua mão. Primeiro encoste o dedo na porta bem próximo da maçaneta e empurre. Agora encoste seu dedo bem 
próximo das dobradiças e tente empurrar. O que você observou?

e. Ao usar um martelo para pregar um prego, por exemplo, se segurarmos o cabo bem na sua extremidade fica mais fácil de pregar do que se segurarmos perto da cabeça do martelo. Explique por que isso acontece.

\section{Experimentação em laboratório virtual}

O roteiro para atividade experimental virtual foi elaborado com base na simulação intitulada "Balançando" do site Phet Interactive Simulations que disponibiliza recursos educacionais livres para professores e estudantes. Assim como a atividade de experimentação convencional, nesta simulação trabalha-se o tema momento de uma força.

Para a realização da atividade experimental ${ }^{2}$ em laboratório virtual será utilizado um Microcomputador previamente preparado pelo professor.

Na sequência, passos experimentais para a execução da atividade.

Passo 1 - Com o computador ligado, dê um clique duplo no ícone "Balança de Equilíbrio" que aparece na área de trabalho, conforme Figura 6, para abrir o experimento no ambiente virtual.

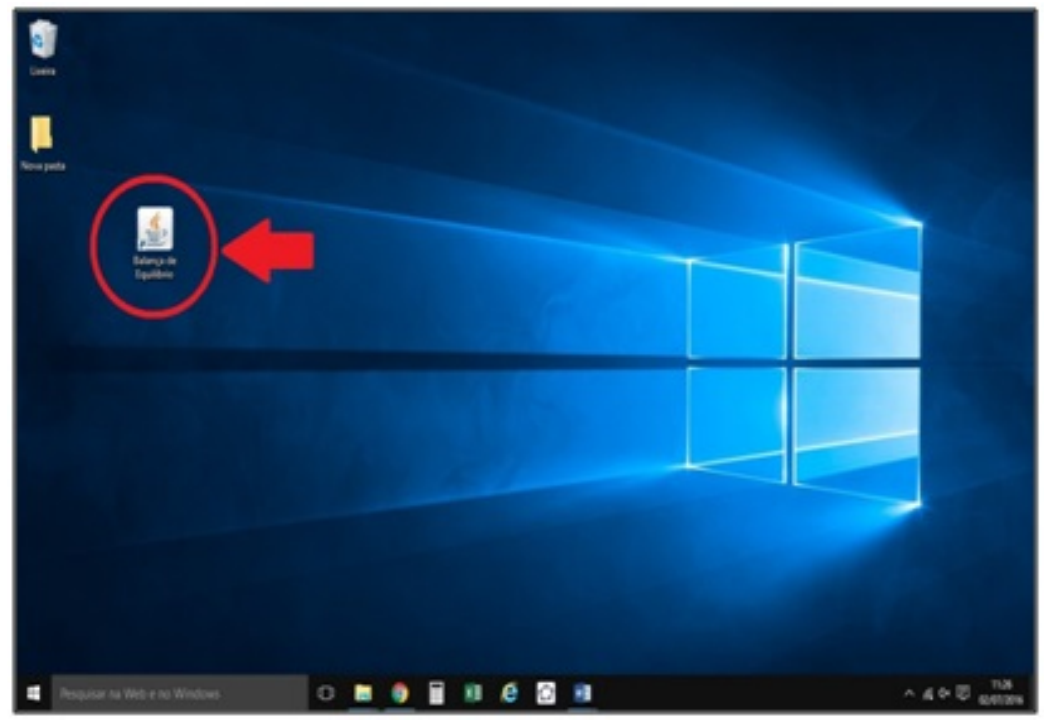

Figura 6: Ícone da área de trabalho.

Passo 2 - Clique na aba "Laboratório de Equilíbrio", em seguida marque a opção "Nível” e clique no botão "Remover Suportes" (Figura 7).

Passo 3 - Equilíbrio de massas. Coloque uma massa (tijolo) de $5 \mathrm{~kg}$ em qualquer posição de um lado da balança e outra massa (tijolo) de $5 \mathrm{~kg}$ do outro lado, de forma que a balança fique em equilíbrio, ou seja,

\footnotetext{
${ }^{2}$ A execução desta atividade experimental, os roteiros para download e instalação do aplicativo utilizado, bem como o vídeo demonstrando todo o processo, além de estarem no anexo deste trabalho, encontram-se disponíveis no website http://labcti.paginas.ufsc.br/momento/
} 


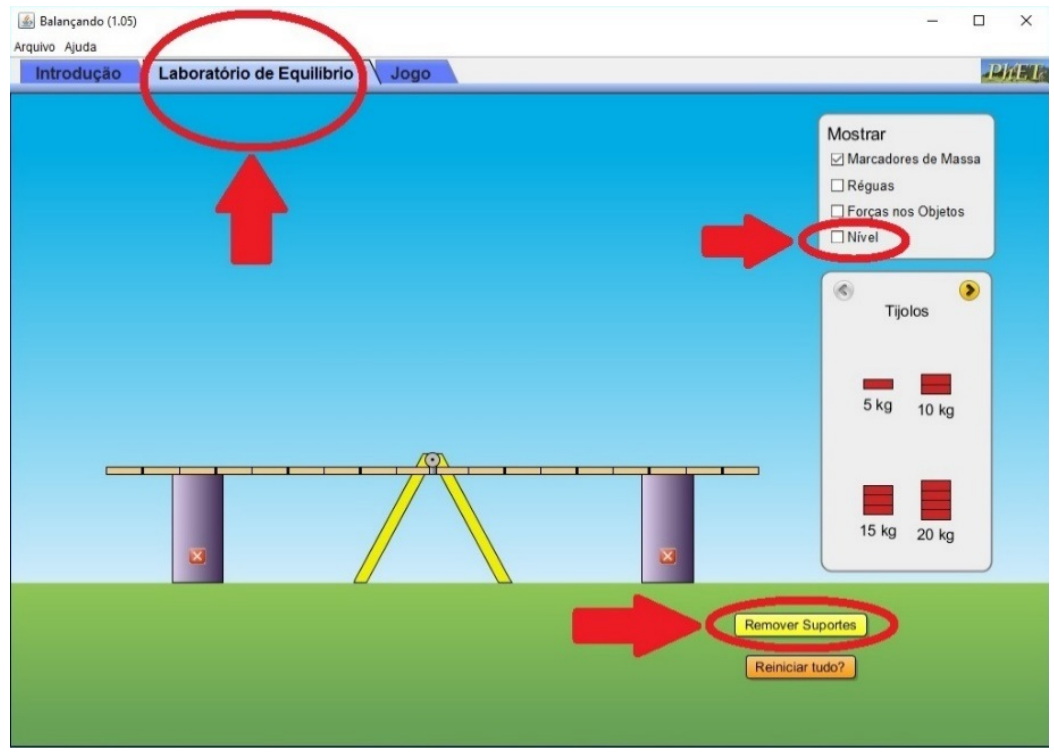

Figura 7: Laboratório de Equilíbrio.

até que a tábua da balança permaneça totalmente na horizontal e as duas setas do Nível fiquem verdes. Para pegar os tijolos basta clicar, arrastá-los e soltá-los na balança (Figura 8).

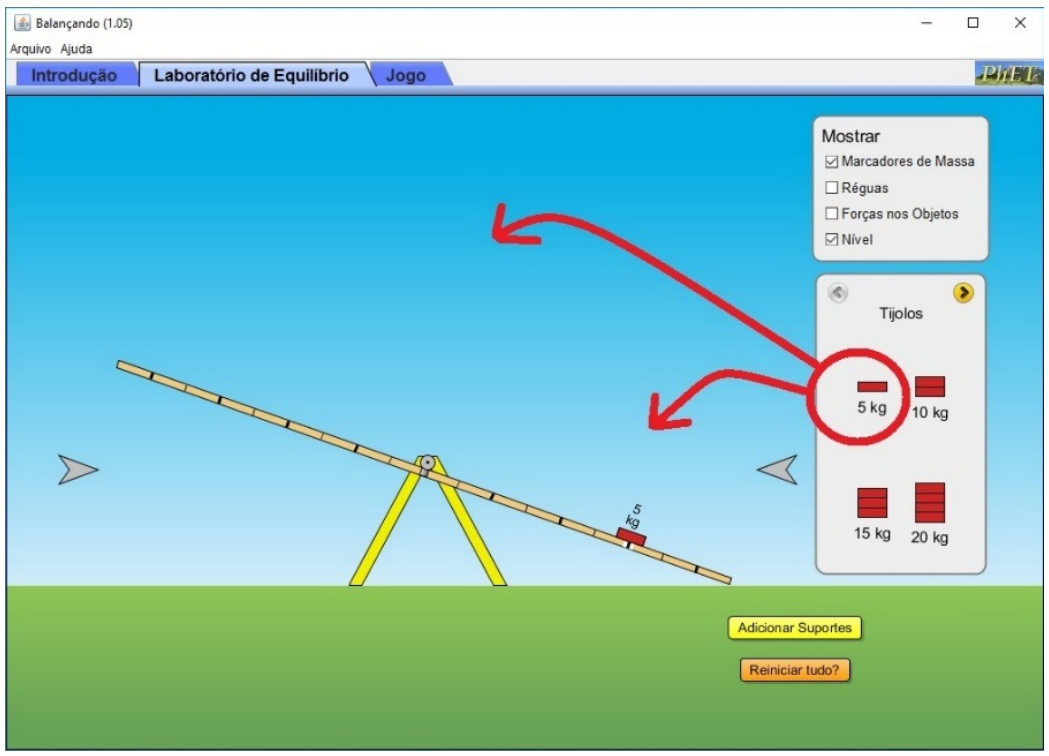

Figura 8: Como colocar as massas na balança.

Conseguiu o equilíbrio? Descreva no relatório o que você fez para conseguir.

Passo 4 - Desafio 1: Coloque de um lado da balança uma massa (tijolo) de $5 \mathrm{~kg}$ em qualquer posição e do outro lado uma massa (tijolo) de $15 \mathrm{~kg}$ de forma que a haste fique em equilíbrio. Conseguiu o equilíbrio? Descreva novamente no relatório o que você fez para conseguir e a que conclusão você chegou. 
Passo 5 - Desafio 2: Coloque na balança 2 massas (tijolos) de $5 \mathrm{~kg}, 1$ massa de $10 \mathrm{~kg}, 1 \mathrm{massa}$ de $15 \mathrm{~kg}$ e outra de $20 \mathrm{~kg}$ distribuindo dos dois lados da balança a fim de encontrar o ponto de equilíbrio. Coloque apenas uma massa por posição.

Conseguiu o equilíbrio? Então, conforme a Figura 9, marque a opção "Réguas" e preencha a Tabela 3 com as medidas de cada massa até o centro da balança. Em seguida, calcule o momento da força, a força peso e a soma dos momentos de cada lado. Considere $g=10 \mathrm{~m} / \mathrm{s}^{2}$ e lembre-se de colocar o sinal negativo para Momentos em que a força peso giraria a balança no sentido horário (conforme Figura 2). As posições das massas na figura são meramente ilustrativas, pois não mostram as posições das massas na condição de equilíbrio e tampouco indicam a certeza do lado que cada massa deve ser colocada.

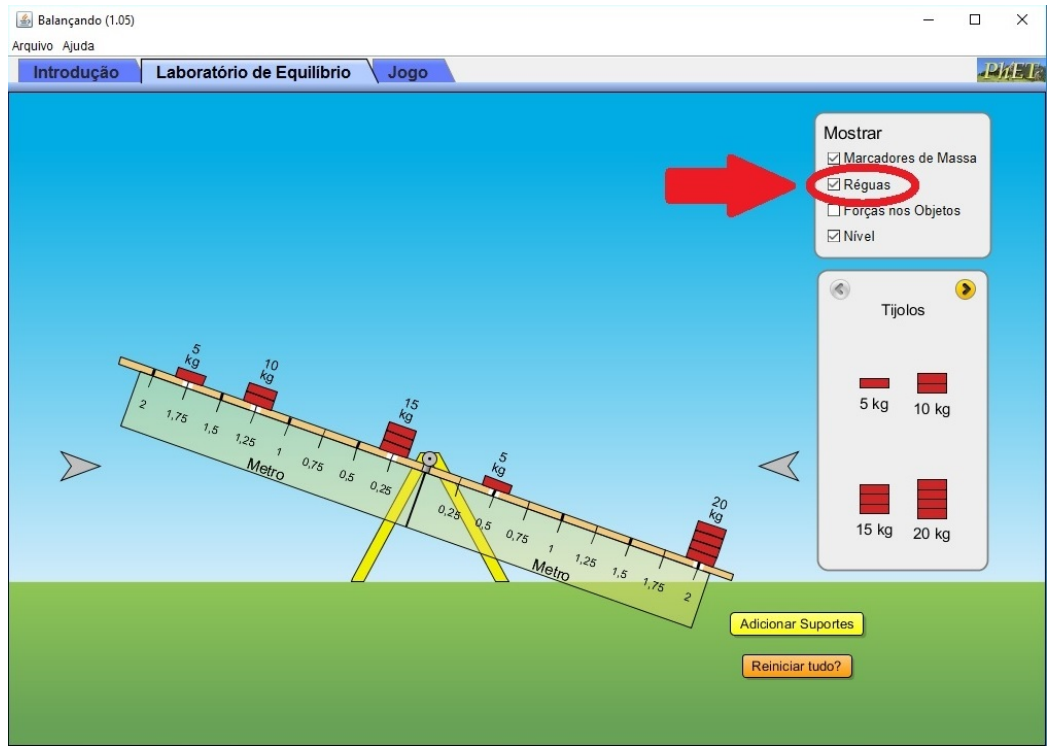

Figura 9: Medições das distâncias das massas em relação ao eixo no programa de simulação.

Passo 6 - Desafio 3: Deixe apenas a massa de $5 \mathrm{~kg}$ na balança. Em seguida, clique 3 vezes na seta indicada na Figura 10 até chegar na lista de massas "Objetos Misteriosos" e coloque o objeto misterioso D no outro lado da balança de forma que ela fique em equilíbrio. É permitido alterar a posição tanto do tijolo de $5 \mathrm{~kg}$ quanto do objeto misterioso D.

Conseguiu o equilíbrio? Então, utilizando o cálculo do Momento, identifique o valor do objeto misterioso D. Depois disso, repita o procedimento utilizando a massa (tijolo) de $10 \mathrm{~kg}$ ao invés da massa de $5 \mathrm{~kg}$. Anote os resultados obtidos e, em seguida, responda às cinco questões a seguir:

a. Na seção Como se faz - Etapa 2 - Passo 1 a soma do momento total do lado esquerdo com o momento total do lado direito foi igual a zero? Por quê?

b. Em um parquinho infantil, Joãozinho, que tem $40 \mathrm{~kg}$ de massa, brinca com seu pai que tem $80 \mathrm{~kg}$. É possível Joãozinho erguer seu pai na gangorra utilizando apenas seu peso? Por quê?

c. Em quais situações no seu dia a dia você gira alguma coisa em torno de um eixo? Em todas elas você pode aplicar o conceito de Momento? 


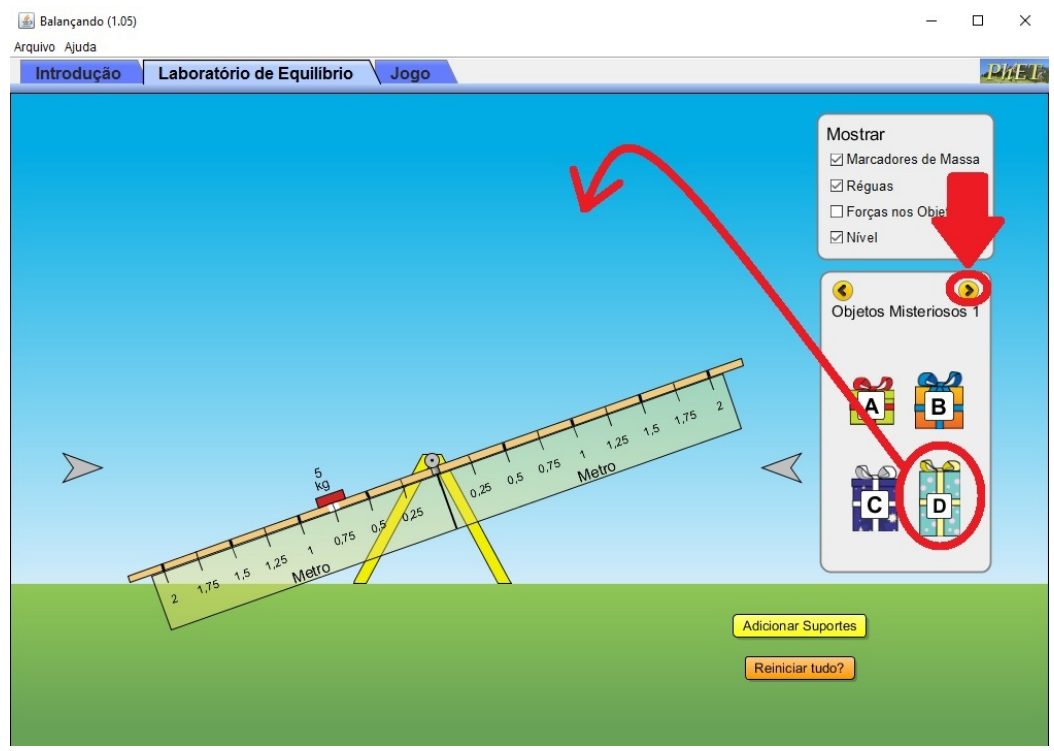

Figura 10: Procedimento para descobrir o valor do objeto misterioso D.

d. Vá até uma porta aberta. Tente empurrar a porta somente com a ponta de um dos dedos de sua mão. Primeiro encoste o dedo na porta bem próximo da maçaneta e empurre. Agora encoste seu dedo bem próximo das dobradiças e tente empurrar. O que você observou?

e. Ao usar um martelo para pregar um prego, por exemplo, se segurarmos o cabo bem na sua extremidade fica mais fácil de pregar do que se segurarmos perto da cabeça do martelo. Explique por que isso acontece.

\section{Comparação entre os métodos convencional e virtual}

Uma comparação entre os experimentos foi realizada no sentido de melhor entender as potencialidades dos experimentos quanto a sua preparação, execução pelo professor e pelo aluno, e eficácia como ferramenta de ensino aprendizagem.

\subsection{Preparação}

O experimento convencional requer muitos materiais, porém todos eles são de baixo custo. Caso o professor queira preparar a experiência, deverá dispender um certo tempo, principalmente na parte que trata da fabricação da balança, para a compra dos materiais, furação de peças, cortes e etc. Para que isso não se torne um motivo para não executar esse método de experimentação, pode-se pedir para que os alunos se dividam em grupos e confeccionem todos os materiais necessários para a atividade que eles farão posteriormente. Além de viabilizar a execução do experimento, o fato de os próprios estudantes se envolverem na fabricação das peças atrai muito mais a atenção deles sobre o que está sendo planejado, pois, ao manipular, explorar e interagir com materiais concretos, os alunos trabalham de forma mais 
prática e aplicada, livrando-se das aulas tradicionais que são repletas de equações e conceitos que parecem somente um preparatório para a vida acadêmica. Além disso, outros fatores podem ser mencionados, como o estímulo do trabalho em grupo e a interação escola/comunidade pois, um trabalho como esse propicia o envolvimento dos pais dos alunos para fornecerem auxílio, seja na procura pela matéria prima ou nos cortes e furações de materiais.

Por sua vez, na forma de experimento em laboratório virtual, a análise de viabilidade e a preparação do experimento deverão ser feitos somente pelo professor. Primeiramente o professor deverá verificar se os computadores possuem os requisitos tecnológicos necessários para a realização do experimento e sua manipulação (sistema operacional, applet e Internet). Em seguida, verificar se o número de computadores disponíveis para a atividade é compatível com o número de alunos da turma a ser aplicada a experiência. No roteiro apresentado foi sugerido o computador, mas pode-se usar também um tablet, por exemplo. O ideal é que fiquem no máximo 3 estudantes por terminal. Se os computadores estiverem aptos, basta entrar no website e copiar o experimento para o computador, conforme o anexo 2. São procedimentos básicos e isso viabiliza muito a utilização desse método. Além disso, algumas escolas possuem uma pessoa cuja função é auxiliar e administrar as salas de informática, ou seja, se for necessário, pode-se apenas entregar o anexo 2 para essa pessoa responsável, e solicitar a ela a possibilidade de deixar todos os computadores do laboratório preparados.

Um aspecto importante sobre a preparação é que o experimento depois de copiado para o computador, deverá ser sempre testado sem conexão com a Internet para se certificar que mesmo sem conexão com a rede Internet (off-line) ele funcionará corretamente.

\subsection{Execução da experimentação pelo professor}

Com certeza há inúmeras vantagens e desvantagens para o professor ao se executar a experimentação convencional ou atividade experimental em ambiente virtual. Nesta seção são relatadas algumas delas.

Ao criar ou seguir um roteiro convencional o professor acaba por ter uma preocupação muito grande com materiais, tamanhos, peças, se são caras, se são raras, se o manuseio é perigoso, por exemplo. A ausência dessas preocupações é uma das vantagens do ambiente virtual, onde não há contato real com essas peças. No entanto, o professor também deverá se preocupar com a dependência que se tem do computador, do hardware dos computadores, das versões dos programas, da instalação e atualização de sistema operacional e outros aplicativos utilizados, p.e. navegador web, applets. E, infelizmente, sabe-se que a falta de equipamentos de ponta ou mesmo até a ausência de computadores nas escolas é uma realidade, i.e., muitas vezes o que o professor tem para trabalhar são poucos computadores e muito antigos. Com relação ao perigo ao manusear algum item no experimento, indiscutivelmente essa é uma grande vantagem do ambiente virtual, onde não há contato com peças nocivas.

No ambiente virtual também diminuem-se os custos e se evitam eventuais desperdícios, além de diminuir o trabalho com transporte e montagem de equipamentos. Também não se tem fatores de interferência externos, como um atrito que não se queira demonstrar ou a resistência do ar que muitas vezes é desconsiderada, por exemplo. Isso pode ser considerado uma vantagem ou desvantagem, depende da intenção do professor para aquele experimento. Nesse caso, cabe ao professor mencionar e explicar aos alunos os modelos que foram criados para a execução da atividade em ambiente virtual. 


\subsection{Execução da experimentação pelo aluno}

Para o aluno também há diferenças ao se fazer uma atividade experimental convencional ou virtual. A limitação quanto à prática da construção e manipulação de peças reais, como enrolar espiras ou cortar uma barra de ferro, é um exemplo. Superando essas limitações, a motivação é incrementada ao ponto de ser provável que queiram até ensinar para os demais de sua família o que aprenderam com a atividade.

Já com o experimento em laboratório virtual, muitos alunos podem não possuir computador próprio e, dessa forma, não conseguirão repetir o experimento em ambiente virtual nas suas casas.

Alguns alunos, porém, justamente por ser uma atividade envolvendo tecnologia (computador), são conquistados para praticar a experiência. Principalmente se a atividade envolver algum tipo de desafio ou jogo. A atividade proposta no roteiro virtual, por exemplo, possui uma aba "jogo" que não foi utilizada no roteiro deste artigo. Nesta aba o aluno deve responder diversas perguntas sobre equilíbrio no menor tempo possível, obtendo pontos de acertos.

\subsection{Considerações sobre a aprendizagem}

Os dois tipos de experimentação possuem os mesmos objetivos, o mesmo embasamento teórico e praticamente os mesmos procedimentos, mesmo acontecendo em ambientes diferentes. No entanto, diferenças podem haver na forma como o aprendizado é estabelecido para o aluno. Na atividade convencional, por exemplo, o professor com um papel muito importante na mediação da aprendizagem, tem ação mais constante fornecendo suporte auxiliar aos alunos na execução do experimento e preparação da atividade. $\mathrm{Na}$ experimentação em laboratório virtual, ao contrário, o próprio software pode fornecer um feedback quando a atividade não estiver correta.

Todavia, são de tamanha importância as atividades experimentais como ferramentas potencializadoras de aprendizagem, seja uma experimentação convencional ou em laboratório virtual. Isso evidencia que a aprendizagem efetivamente acontece em ambos os casos.

\section{Considerações Finais}

Neste trabalho foram apresentadas duas formas de experimentação para ensino do Momento de uma força em Física. Apesar de existirem diferenças vantajosas e desvantajosas entre a experimentação covencional e a experimentação em laboratório virtual apresentadas, todos os dois tipos de experimentação possuem potencial para a aprendizagem.

A experimentação convencional aparentemente exige mais trabalho na preparação, no entanto permite ao estudante se envolver na construção dos objetos que serão usados no experimento e isso é frequentemente motivador para o estudante. Dessa forma, o estudante também tem o contato com as peças e sente a diferença de peso entre as massas, ou seja, sem precisar ver a indicação do valor, ele já é capaz de identificar que uma é mais pesada que a outra e tenta assim, intuitivamente encontrar uma solução para equilibrar as duas. Ele traz também à tona o sentimento de prática, de "colocar a mão na massa".

$\mathrm{Na}$ experimentação em laboratório virtual ou com programa de simulação chama a atenção dos alunos se tratar do uso de tecnologia computacional. As crianças e adolescentes são atraídas pela informática, 
então o simples fato de eles poderem utilizar o computador na aula de Física já é uma grande conquista de interesse por parte dos estudantes. Infelizmente não são todas as escolas que possuem computadores aptos para fazer os experimentos.

Os dois experimentos que foram propostos apresentam-se adequados para serem compreendidos por alunos do $9^{\circ}$ ano do Ensino Fundamental. O laboratório virtual, por exemplo, pode ser executado até mesmo por pessoas que não tem um conhecimento prévio de informática, pois são autoexplicativos. Isso é importante em uma atividade de ambiente virtual, pois dependendo da complexidade dela, pode ser inviável para uma região onde as pessoas são mais leigas na área da tecnologia da informação.

Enfim, a conclusão que se chega é que ao ensinar Momento de uma Força para as crianças do $9^{\circ}$ ano do Ensino Fundamental II, ambas as propostas são viáveis desde que se tenham os materiais necessários e o professor se sinta preparado para reproduzi-los com os alunos. Uma possibilidade seria a de criar uma proposta de realização d o experimento em laboratório virtual e em seguida criar a própria balança. Ou ainda pode-se inverter a ordem, criando-se primeiramente a balança fazendo o experimento convencional e, em seguida, utilizar a aba jogos do laboratório virtual como forma de exercício. As vantagens e desvantagens aqui mencionadas poderão auxiliar os professores a tomar uma decisão sobre como proceder de maneira mais adequada ao seu plano de ensino, sequência didática e sua disponibilidade de recursos. $\mathrm{O}$ professor pode optar por fazer em uma mesma escola a experimentação convencional para uma turma e a experimentação em ambiente virtual para outra. O próprio professor, maestro de suas aulas e inspirador da motivação dos alunos é quem deve avaliar.

\section{Referências}

[1] SANTOS, E.I; PIASSI, L. P. C.; FERREIRA, N. C. Atividades Experimentais de baixo custo como estratégia de construção da autonomia de professores de Física: uma experiência em formação continuada. In: IX Encontro Nacional de Pesquisa de Física. Belo Horizonte, 2004.

[2] LIBÂNIO, J.C. Didática. São Paulo: Cortez, 2006.

[3] ROSITO, B. A. O Ensino de Ciências e a Experimentação. In: MORAES, R. (org.). Construtivismo e Ensino de Ciências: Reflexões Epistemológicas e Metodológicas. Porto Alegre: EDIPUCRS, 2008.

[4] RAMALHO JUNIOR, F.; FERRARO, N. G.; SOARES, P. A. T. Os fundamentos da Física - vol 1. $9^{\mathrm{a}}$ ed. São Paulo: Editora Moderna, 2007. 